\title{
Investigation of propane and $n$ - butane hydrate formation condition and determination of equilibrium pressure
}

\author{
Somayeh Slehfekr ${ }^{a}$,Sajjad Porgar*b,Nejat Rahmanian
}

Department of engineering, Shahr-e-Qods-shahryar branch,Islamic azad university, Tehran,Iran

Department of Chemical Engineering, South Tehran Branch, Islamic Azad University, Tehran, Iran

Department of Chemical Engineering, University of Bradford, Bradford, UK

*st_s_porgar@azad.ac.ir

\begin{abstract}
:
The purpose of this study is determine the equilibrium conditions for the formation of a mixture of propane and normal butane hydrates including temperature, pressure and mole fraction. In order to prevent the formation of hydrates in the cooling path, it is necessary to examine the conditions of hydrate formation and provide solutions. Modeling of hydrate formation conditions was performed using Hydoff software and compared with experimental results in this field, which obtained acceptable error percentage. The range of temperature is between $267-276{ }^{\circ} \mathrm{C}$ and the molar percentage of propane is $0.7,0.8$ and 0.9 and the mathematical equation was presented to predict hydrate formation. By analyzing the results, it was found that by increasing the concentration of ethane in the presence of other compounds, hydrate growth increased and hydrates formed more stable, also by increasing the concentration of propane and normal butane the amount of equilibrium pressure will decrease.

Keywords: Hydrate, Propane, Normal butane, Equilibrium pressure
\end{abstract}

\section{Introduction}

Inhibitors cannot be used because of the need for high purity propane production. Due to the propane storage conditions at certain pressures and temperatures, the effect of reservoir temperature on hydrate formation cannot be exploited. The high percentage of ethane in liquid propane causes problems such as clogging in the chillers and reducing their cooling efficiency. Propane produced has various impurities such as ethane, normal butane, isobutane and pentane and less than $10 \mathrm{ppm}$ water. Propane is stored in reservoirs at specified temperatures, which increases with the increase in ethane and isopentane concentrations, increasing the equilibrium pressure of hydrate formation, which will practically make the hydrate harder to form, and these impurities are negligible but have a major impact on the thermodynamic and thermal properties.

The history of gas hydrate discovery is divided into three main periods. The first period is of interest to the formation of gas hydrates scientifically, because the accumulation of water and gas together and as a hydrate phase due to inconsistency with scientific conditions and information at that time was an interesting phenomenon. This period began precisely in 1810 with the discovery of hydrates and continues to this day. The second period is about 1934, when more extensive research was done on the gas hydrate structure, the fact that the congestion of natural gas pipelines at low temperatures was not due to freezing of water and ice, and that the conditions were favorable for the formation of gas hydrates. In other words, this is part of the history of discovering natural gas hydrates about problems caused by the formation of gas hydrates in unwanted situations. On the other hand, in the 1960s, with the discovery of large 
quantities of these molecules in the lower layers of the earth that contain large amounts of natural gas, much of the history of hydrates was devoted to the fact that nature hydrates has produced millions of years ago. It also reinforced the theory of the existence of water on other planets in the form of hydrates as humans made it possible to reach other planets, such as Mars and discover hydrate sources outside the Earth's atmosphere. Therefore, the present age is the intersection of all three periods of hydrate history [1].

After a hundred years of observing the first gas hydrate crystals in the laboratory, gas hydrates were raised only in scientific circles, and the discussions were focused on only two major axes:

- What molecules are capable of forming hydrate crystals?

- What are the requirements for forming a hydrate crystal?

With the rapid growth of the oil and gas industry and the problems caused by the closure of natural gas pipelines and the need for industry to address this problem and the awareness of the conditions for the formation of various gas hydrates, industry and governments have joined scientific circles and demand newer studies of these molecules have been made in areas such as crystal structure and their properties, conditions of formation, how to prevent formation and so on. For this reason, over the last forty years, the hydrate crystals and all the issues involved with them have attracted a great deal of scientific study [2].

Different methods such as gas density graphs, Joule-Thomson expansion, empirical equations, statistical thermodynamics and artificial neural networks have been proposed to predict gas hydrate formation conditions (pressure or temperature). The best way to determine hydrate formation conditions is empirically measured using temperature, pressure and gas composition parameters, but since empirical measurements are impossible due to time and cost. The hydrate formation conditions for any given gas are not empirically feasible [3].

\section{Methods for predicting hydrate formation conditions}

\subsection{Prediction by using empirical graphs}

From 1945, gas density diagrams were obtained by Katz and his colleagues. In these graphs the pressure and temperature of the hydrate formation are related to the gas density. Statistical analysis has shown that for a gas mixture with different percentages of components but with the same density, the predicted pressure of hydrate formation has a 50\% error. These graphs are plotted using Joule-Thomson gas density and expansion graphs and provide the permitted expansion rates for natural gas of different densities. This method has an average error of 10\% [4-6].

\subsection{Statistical Thermodynamics Theory of Van der Waals}

The most accurate and accurate statistical techniques were based on the theory of Van der Waals statistical thermodynamics in 1959 to determine the conditions of formation of gas hydrates in equilibrium with liquid water $[7,8]$.

\subsection{Thermodynamic Model of Parish and Perznitz}

In this model, the 3-parameter potential of Kihara is used to increase the accuracy rather than the energy of the molecular potential of Lennard Jones. Then the Langmuir constant is calculated and with temperature the hydrate formation pressure is predicted from the van der Waals equation $[9,10,11]$. Although experimental methods have often been replaced by more advanced thermodynamic methods, the need for and use of 
manual and experimental calculations in laboratory methods is still unavoidable. Experimental methods performed through solid-vapor phase equilibrium constants have been the most widely used.

\section{Modeling}

These systems include the liquid-hydrate-gas phases. Under hydrate formation, the gas phase is assumed to be pure and water-free, which is also a good assumption due to the high pressure and low temperature. There are many thermodynamic models available to predict hydrate formation from the various modifications and modifications suggested by Vdwp's model proposed by Van der Waals [12]. Authors and researchers have recently suggested that alternate static mechanisms underlie the formation of hydrates. The basis and purpose of the vdw-p model is based on the assumption of similarity between hydrate formation and Langmuir absorption. Although the adsorption mechanism is capable of interpreting non-stoichiometric properties and states of hydrates, there are many differences between the two processes. The equations used can be summarized as follows.

Equation Summary to Determine Fugacity of Water in Hydrate [3]

$f_{w}^{H}=f_{w 0} \exp \left[\frac{\mu_{w}^{H}-g_{w 0}}{R T}\right]$

Where $f_{w 0}$ is 1 bar, $g_{w 0}$ is the Gibbs energy of pure water in the ideal gas state at 1 bar:

$$
\begin{aligned}
& \mu_{w}^{H}=g_{w}^{\beta}+R T \sum_{i} \vartheta_{i} * \operatorname{Ln}\left(1-\sum_{J} \theta_{i J}\right)+R T L n \gamma_{w}^{H} \\
& \theta_{i J}=\frac{C_{i J f_{J}}}{1+C_{i J f_{J}}} \\
& C_{J, i}=\frac{4 \pi}{k T} \int_{0}^{R_{1}-a_{J}} \exp \left[\frac{\sum_{n} \omega_{J, n}(r)}{k T}\right] r^{2} d r \\
& w_{J n}(r)=2 z_{n} \varepsilon_{J} J \frac{\sigma_{J}^{12}}{R_{n}^{11}}\left(\delta^{10}+\frac{a_{J}}{R_{n}} \delta^{11}\right)-\frac{\sigma_{J}^{6}}{R_{n}^{5} r}\left(\delta^{4}+\frac{a_{J}}{R_{n}} \delta^{5}\right) \\
& \text { Where } \delta^{N}=\frac{1}{N}\left[\left(1-\frac{r}{R_{n}}-\frac{a_{J}}{R_{n}}\right)^{-N}-\left(1+\frac{r}{R_{n}}-\frac{a_{J}}{R_{n}}\right)^{-N}\right. \\
& \frac{g_{w}^{\beta}}{R T}=\frac{g_{w_{0}}^{\beta}}{R T_{0}}-\int_{T_{0}}^{T} \frac{h_{w}^{\beta}}{R T^{2}} d T+\int_{P_{0}}^{P} \frac{V_{w}^{\beta}}{R T} d P \\
& h_{w}^{\beta}=h_{w_{0}}^{\beta}+\int_{T_{0}}^{T} C_{P} \beta d T \\
& V_{w}^{\beta}=\left(\alpha_{0}^{*}\right)^{3} \exp \left[\alpha_{1}\left(T-T_{0}\right)+\alpha_{2}\left(T-T_{0}\right)^{2}+\alpha_{3}\left(T-T_{0}\right)^{3}-k\left(P-P_{0}\right)\right] \\
& \ln \gamma_{w}^{H}=\frac{\Delta g_{w_{0}}^{\beta}}{R T_{0}}+\frac{\Delta h_{w_{0}}^{\beta}}{R}\left(\frac{1}{T}-\frac{1}{T_{0}}\right)+\int_{P_{0}}^{P} \frac{\Delta v^{H}}{R T} d P \\
& \Delta g_{w_{0}}^{\beta}=a \Delta v_{0}^{H} \text { and } \Delta h_{w_{0}}^{\beta}=a \Delta v_{0}^{H} \\
& \Delta v^{H}=v^{H}-v^{\beta}
\end{aligned}
$$




$$
\begin{aligned}
& v^{H}=v_{0} \exp \left[\alpha_{1}\left(T-T_{0}\right)+\alpha_{2}\left(T-T_{0}\right)^{2}+\alpha_{3}\left(T-T_{0}\right)^{3}-k\left(P-P_{0}\right)\right] \\
& v_{0}=\left(a_{0}^{*}+\sum_{i} N_{i} \sum_{J} f\left(\theta_{i J}\right) \Delta r_{i J}\right)^{3} \\
& 5^{12} \text { cages: } f\left(\theta_{i J}\right)=\frac{\left(1+\dot{\eta}_{i}\right) \theta_{i J}}{\dot{\eta}_{i} \theta_{i J}} \exp \left[D_{J}-\bar{D}\right) \\
& 5^{12} 6^{2} \text { and } 5^{12} 6^{4} \text { cages: } f\left(\theta_{i J}\right)=\frac{\left(1+\dot{\eta}_{i}\right) \theta_{i J}}{\eta_{i} \theta_{i J}} \exp \left[D_{J}-\bar{D}\right)
\end{aligned}
$$

\section{Results}

Extensive studies of hydrate formation conditions have been carried out by various researchers so far, and modifications have been made to the original Van der walls model so that it is now able to accurately predict thermodynamic conditions including temperature and pressure of hydrate formation. In the present model, the results are presented solely to predict the performance of the model.

Modeling results were obtained using Hydoff software and propane molar fraction as well as temperature was entered as software and equilibrium pressure was obtained. In Table 1, the results obtained using software were compared with the experimental results of Kamath \& Holder and the average error rate for the data was $10 \%$.

\begin{tabular}{|c|c|c|c|c|c|c|c|c|c|}
\hline \multicolumn{6}{|c|}{ Table 1- Comparison between modeling and Kamath \& Holder exeperimental investigation[13] } \\
\hline$\% \mathrm{CH}_{3}$ & $\mathrm{~T}(\mathrm{~K})$ & $\begin{array}{c}\mathrm{P} \\
\mathrm{kPa}) \\
- \\
\mathrm{EXP}\end{array}$ & $\begin{array}{c}\mathrm{P}(\mathrm{kPa})- \\
\text { MODELING }\end{array}$ & $\%$ Error & $\% \mathrm{CH}_{3}$ & $\mathrm{~T}(\mathrm{~K})$ & $\begin{array}{c}\mathrm{P} \\
(\mathrm{kPa})- \\
\mathrm{EXP}\end{array}$ & $\begin{array}{c}\mathrm{P}(\mathrm{kPa})- \\
\text { MODELING }\end{array}$ & \%Error \\
\hline 90.3 & 260.15 & 110.1 & 114.96 & 4.41 & 83.5 & 248.15 & 69.03 & 76.015 & 10.11 \\
\hline 90.3 & 257.85 & 99.26 & 105.134 & 5.91 & 83.5 & 245.85 & 66.76 & 68.956 & 3.28 \\
\hline 90.3 & 254.35 & 83.86 & 91.507 & 9.11 & 83.5 & 242.45 & 59.59 & 59.538 & 0.08 \\
\hline 90.3 & 248.65 & 67.09 & 72.407 & 7.92 & 70 & 253.75 & 97.16 & 111.651 & 14.91 \\
\hline 90.3 & 245.05 & 61.23 & 62.15 & 1.50 & 70 & 250.95 & 85.86 & 99.794 & 16.22 \\
\hline 90.3 & 242.05 & 49.2 & 54.598 & 10.97 & 70 & 245.65 & 70.07 & 79.859 & 13.97 \\
\hline 83.5 & 250.55 & 76.36 & 84.013 & 10.02 & 70 & 241.85 & 55.38 & 67.671 & 22.19 \\
\hline 83.5 & 249.55 & 73.37 & 80.595 & 9.84 & 70 & 238.25 & 46.9 & 57.674 & 22.97 \\
\hline
\end{tabular}

A comparison was also made between the results of the software with the experimental results of Paranjpe et al and a mean error of 3.64\% was reported indicating high accuracy of the modeling results.

\begin{tabular}{|c|c|c|c|c|c|c|c|c|c|}
\hline \multicolumn{8}{|c|}{ Table 2-Comparison between modeling and Paranjpe et al exeperimental investigation [14] } \\
\hline$\% \mathrm{CH}_{3}$ & $\mathrm{~T}(\mathrm{~K})$ & $\begin{array}{c}\mathrm{P}(\mathrm{kPa}) \\
\text {-EXP }\end{array}$ & $\begin{array}{c}\mathrm{P}(\mathrm{kPa})- \\
\text { MODELING }\end{array}$ & $\%$ Error & $\% \mathrm{CH}_{3}$ & $\mathrm{~T}(\mathrm{~K})$ & $\begin{array}{c}\mathrm{P}(\mathrm{kPa}) \\
\text {-EXP }\end{array}$ & $\begin{array}{c}\mathrm{P}(\mathrm{kPa})- \\
\text { MODELING }\end{array}$ & \%Error \\
\hline 86.4 & 271.2 & 153.1 & 180.049 & 14.96 & 80.3 & 271.2 & 191.7 & 191.885 & 0.096 \\
\hline 87.9 & 271.2 & 170.9 & 177.357 & 3.64 & 76 & 271.2 & 204.1 & 201.207 & 1.43 \\
\hline 86.1 & 271.2 & 177.9 & 180.596 & 1.49 & 67.6 & 271.2 & 217.9 & 217.299 & 0.27 \\
\hline
\end{tabular}


In another study by Paranjpe et al, they reported experimental results for propane and normal butane hydrates and compared the results to model accuracy and reported an average error rate of $4.2 \%$.

\begin{tabular}{|c|c|c|c|c|c|c|c|c|c|}
\hline \multicolumn{7}{|c|}{ Table 3- Comparison between modeling and Paranjpe et al exeperimental investigation[15] } \\
\hline$\% \mathrm{CH}_{3}$ & $\mathrm{~T}(\mathrm{~K})$ & $\begin{array}{c}\mathrm{P} \\
(\mathrm{kPa})- \\
\mathrm{EXP}\end{array}$ & $\begin{array}{c}\mathrm{P}(\mathrm{kPa})- \\
\text { MODELING }\end{array}$ & $\%$ Error & $\% \mathrm{CH}_{3}$ & $\mathrm{~T}(\mathrm{~K})$ & $\begin{array}{c}\mathrm{P}(\mathrm{kPa})- \\
\text { EXP }\end{array}$ & $\begin{array}{c}\text { P (kPa)- } \\
\text { MODELING }\end{array}$ & $\%$ Error \\
\hline 99.6 & 275.2 & 269.6 & 262.561 & 2.6 & 81.7 & 274.2 & 269.6 & 253.932 & 5.81 \\
\hline 92.4 & 275.2 & 281.3 & 281.093 & 0.07 & 100 & 273.2 & 169.6 & 171.826 & 1.31 \\
\hline 89.4 & 275.2 & 302 & 289.583 & 4.1 & 96.9 & 273.2 & 171.7 & 177.019 & 3.09 \\
\hline 87.3 & 275.2 & 308.9 & 296.129 & 4.13 & 95.3 & 273.2 & 177.9 & 179.659 & 0.98 \\
\hline 88 & 275.2 & 317.2 & 293.753 & 7.39 & 93.8 & 273.2 & 183.4 & 182.206 & 0.65 \\
\hline 100 & 274.2 & 219.3 & 211.868 & 3.38 & 86.4 & 273.2 & 208.2 & 195.874 & 5.92 \\
\hline 96.1 & 274.2 & 228.2 & 219.542 & 3.79 & 82.8 & 273.2 & 220.3 & 203.299 & 7.71 \\
\hline 93.3 & 274.2 & 240.6 & 225.374 & 6.32 & 78.8 & 273.2 & 227.5 & 212.201 & 6.72 \\
\hline 90.6 & 274.2 & 244.8 & 231.29 & 5.51 & 72.5 & 273.2 & 244.1 & 227.935 & 6.62 \\
\hline
\end{tabular}

The overall results obtained from the modeling by software are presented in Table 4 and, as can be seen, the hydrate formed is structure II, and the molar percentage of propane in the hydrate formed is also calculated and reported. In this table, the variables of hydrate formation, temperature and propane content were input feed and the pressure was obtained as a result of the modeling.

Conditions of hydrate formation include pressure and temperature, water molecule and gas molecule. The hydrate formation process has very similar steps to the crystallization process and involves two stages of nucleation and growth. Studies have shown that if the conditions are right, the hydrate crystal does not form immediately, but rather it takes time for the necessary arrangement between the water molecules to form cages [16].

\begin{tabular}{|c|c|c|c|c|c|c|c|}
\hline \multicolumn{7}{|c|}{ Table 4- Three phase equilibrium condition- Propane ( Equilibrium Hydrate Structure II) } \\
\hline $\begin{array}{c}\text { Temperature } \\
(\mathrm{K})\end{array}$ & $\begin{array}{c}\text { Equilibrium } \\
\text { pressure } \\
(\mathrm{KPa})\end{array}$ & $\begin{array}{c}\text { Feed } \\
\text { Composition }\end{array}$ & $\begin{array}{c}\text { Composition } \\
\text { at Equilibrium }\end{array}$ & $\begin{array}{c}\text { Temperature } \\
(\mathrm{K})\end{array}$ & $\begin{array}{c}\text { Equilibrium } \\
\text { pressure } \\
(\mathrm{KPa})\end{array}$ & $\begin{array}{c}\text { Feed } \\
\text { Composition }\end{array}$ & $\begin{array}{c}\text { Composition } \\
\text { at Equilibrium }\end{array}$ \\
\hline 260.150 & 114.960 & 0.903 & 0.9864 & 275.20 & 262.561 & 0.996 & 0.9994 \\
\hline 245.050 & 62.150 & 0.903 & 0.9883 & 275.20 & 298.943 & 0.8630 & 0.9775 \\
\hline 245.650 & 79.859 & 0.700 & 0.9548 & 275.20 & 293.753 & 0.880 & 0.9806 \\
\hline 254.350 & 91.507 & 0.903 & 0.9871 & 274.20 & 211.868 & 1.00 & 1.00 \\
\hline 248.650 & 72.407 & 0.903 & 0.9879 & 274.20 & 225.374 & 0.933 & 0.9897 \\
\hline 257.850 & 105.134 & 0.9030 & 0.9867 & 274.20 & 253.932 & 0.817 & 0.9686 \\
\hline 250.550 & 84.013 & 0.835 & 0.9775 & 274.20 & 231.290 & 0.906 & 0.9851 \\
\hline 242.050 & 54.598 & 0.903 & 0.9887 & 273.20 & 171.826 & 1.00 & 1.00 \\
\hline
\end{tabular}




\begin{tabular}{|c|c|c|c|c|c|c|c|}
\hline 241.850 & 67.671 & 0.7000 & 0.9566 & 273.20 & 177.019 & 0.969 & 0.9954 \\
\hline 249.550 & 80.595 & 0.835 & 0.9777 & 273.20 & 179.659 & 0.957 & 0.9929 \\
\hline 253.750 & 111.651 & 0.700 & 0.9510 & 273.20 & 182.206 & 0.938 & 0.9905 \\
\hline 250.950 & 99.794 & 0.700 & 0.9523 & 273.20 & 189.908 & 0.895 & 0.9833 \\
\hline 238.250 & 56.674 & 0.700 & 0.9583 & 273.20 & 212.201 & 0.788 & 0.9627 \\
\hline 271.20 & 191.885 & 0.803 & 0.9664 & 273.20 & 227.935 & 0.725 & 0.9483 \\
\hline 271.200 & 201.207 & 0.760 & 0.9572 & 273.20 & 198.874 & 0.864 & 0.9777 \\
\hline 271.20 & 180.049 & 0.864 & 0.9781 & 273.20 & 203.299 & 0.828 & 0.9709 \\
\hline 271.20 & 217.299 & 0.676 & 0.9416 & 275.20 & 289.583 & 0.894 & 0.9830 \\
\hline 275.20 & 296.129 & 0.8721 & 0.9791 & 275.20 & 281.093 & 0.924 & 0.9882 \\
\hline
\end{tabular}

Given the obtained results and considering that the error rate was an acceptable value, it can be concluded that the modeling can predict the behavior of the propane and normal butane hydrate mixtures and hence at three mole percent $0.7,0.8$ and 0.9 of propane were modeled at temperatures of 267-276 K and the results were reported and for each mole percent a mathematical relationship between temperature and pressure was presented to predict hydrate formation behavior.

\begin{tabular}{|c|c|c|c|c|c|c|c|c|}
\hline \multicolumn{10}{|c|}{ Table 5- modeling of hydrate formation } \\
\hline$\% \mathrm{CH}_{3}$ & $\mathrm{~T}(\mathrm{~K})$ & $\mathrm{P}(\mathrm{kPa})$ & $\% \mathrm{CH}_{3}$ & $\mathrm{~T}(\mathrm{~K})$ & $\mathrm{P}(\mathrm{kPa})$ & $\% \mathrm{CH}_{3}$ & $\mathrm{~T}(\mathrm{~K})$ & $\mathrm{P}(\mathrm{kPa})$ \\
\hline 0.7 & 267 & 185.534 & 0.8 & 267 & 165.272 & 0.9 & 267 & 149.196 \\
\hline 0.7 & 268 & 192.425 & 0.8 & 268 & 171.277 & 0.9 & 268 & 154.758 \\
\hline 0.7 & 269 & 199.493 & 0.8 & 269 & 177.891 & 0.9 & 269 & 160.450 \\
\hline 0.7 & 270 & 206.784 & 0.8 & 270 & 184.417 & 0.9 & 270 & 166.254 \\
\hline 0.7 & 271 & 214.274 & 0.8 & 271 & 191.145 & 0.9 & 271 & 172.192 \\
\hline 0.7 & 272 & 221.968 & 0.8 & 272 & 198.043 & 0.9 & 272 & 178.741 \\
\hline 0.7 & 273 & 229.863 & 0.8 & 273 & 205.151 & 0.9 & 273 & 185.181 \\
\hline 0.7 & 274 & 263.376 & 0.8 & 274 & 247.977 & 0.9 & 274 & 223.172 \\
\hline 0.7 & 275 & 305.309 & 0.8 & 275 & 305.323 & 0.9 & 275 & 275.916 \\
\hline 0.7 & 276 & 356.345 & 0.8 & 276 & 356.43 & 0.9 & 276 & 341.402 \\
\hline
\end{tabular}

In Figures 1 to 3, diagrams of hydrate formation pressure are plotted in terms of temperature at three moles of propane, and as indicated in each of the three diagrams the hydrate formation pressure increases with increasing temperature. Primary factors affecting the formation of hydrates include the fluid phase that is at or below dew point, temperature, pressure and gas composition, and other parameters including kinetics, system salinity, surface physical type on which hydrate crystals are present, the rate of mixing and density of the system. Generally, hydrate formation occurs with increasing pressure and decreasing temperature until the formation conditions are reached, and increasing the driving force reduces the formation time. Controlling or removing one of the key factors in hydrate formation prevents hydrate formation by reducing the pressure of the gas, dehydrating the system, using insulation or heating to maintain system temperature outside the hydrate formation area. Most of these methods are impractical and sometimes costly. 


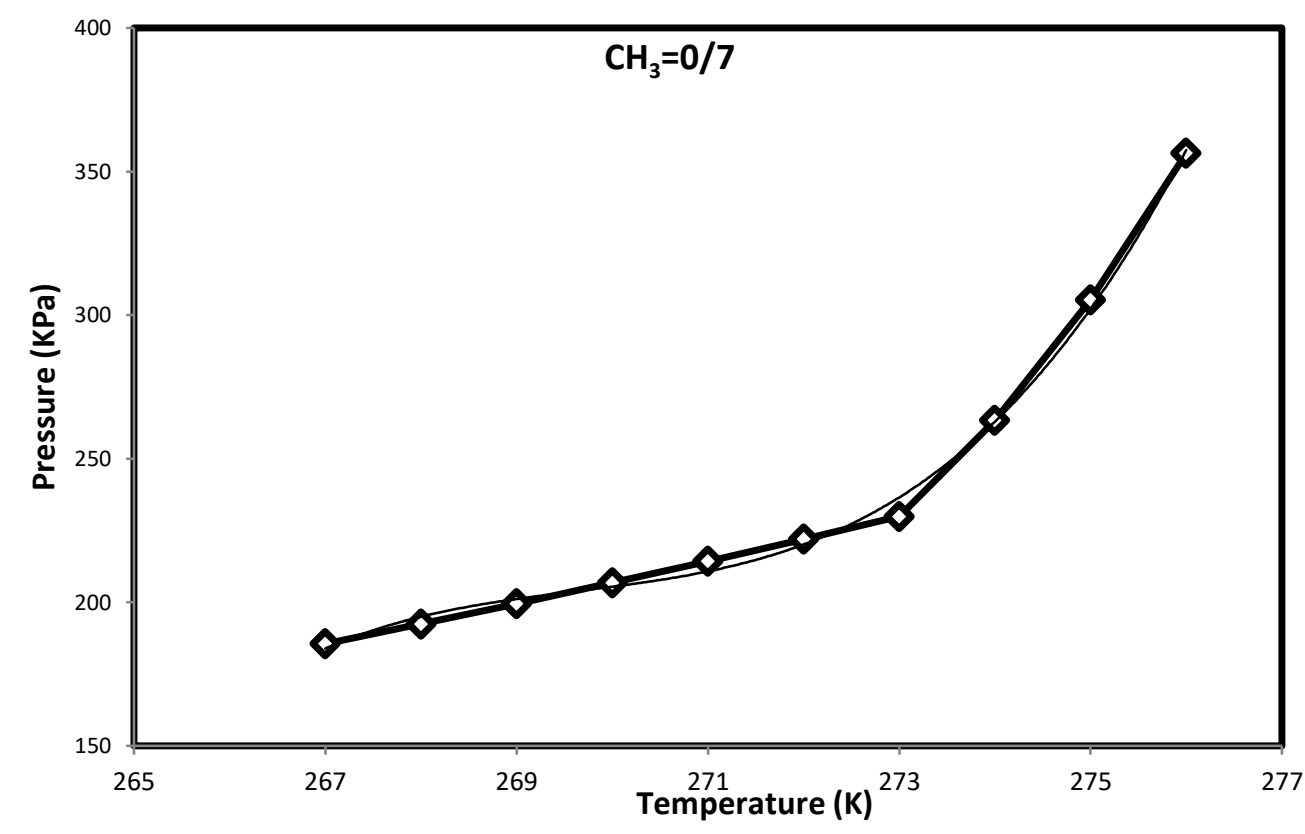

Figure 1- Equilibrium pressure versus temperature @ $\% \mathrm{CH}_{3}=0.7$

$$
\begin{array}{ll}
\mathrm{P}(\mathrm{KPa})=0 / 4953 \mathrm{~T}^{3}-400 / 69 \mathrm{~T}^{2}+108048 \mathrm{~T}-1 \mathrm{E}+07 & @ \% \mathrm{CH}_{3}=0.7 \\
\mathrm{P}(\mathrm{KPa})=0 / 5776 \mathrm{~T}^{3}-466 / 92 \mathrm{~T}^{2}+\mathrm{T}-1 \mathrm{E}+07 & @ \% \mathrm{CH}_{3}=0.8 \\
\mathrm{P}(\mathrm{KPa})=0 / 683 \mathrm{~T}^{3}-552 / 62 \mathrm{~T}^{2}+149053 \mathrm{~T}-1 \mathrm{E}+07 & @ \% \mathrm{CH}_{3}=0.9
\end{array}
$$

In the mathematical equations 16 to 18 , the propane hydrate formation is presented in the molar fraction and the desired temperature limit, and these equations can be used to predict the hydrate formation conditions.

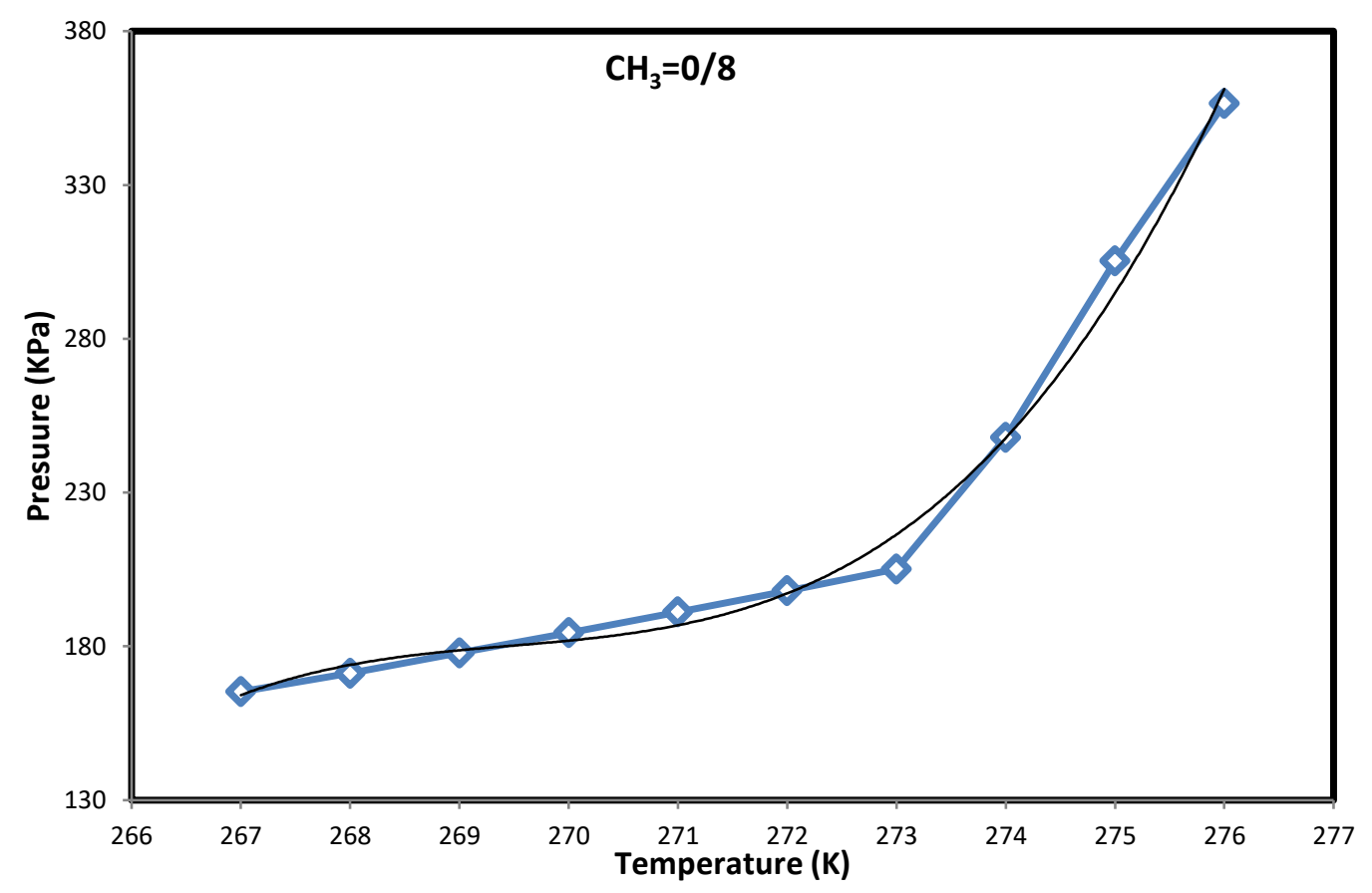

Figure 2- Equilibrium pressure versus temperature @ \% $\mathrm{CH}_{3}=0.8$ 


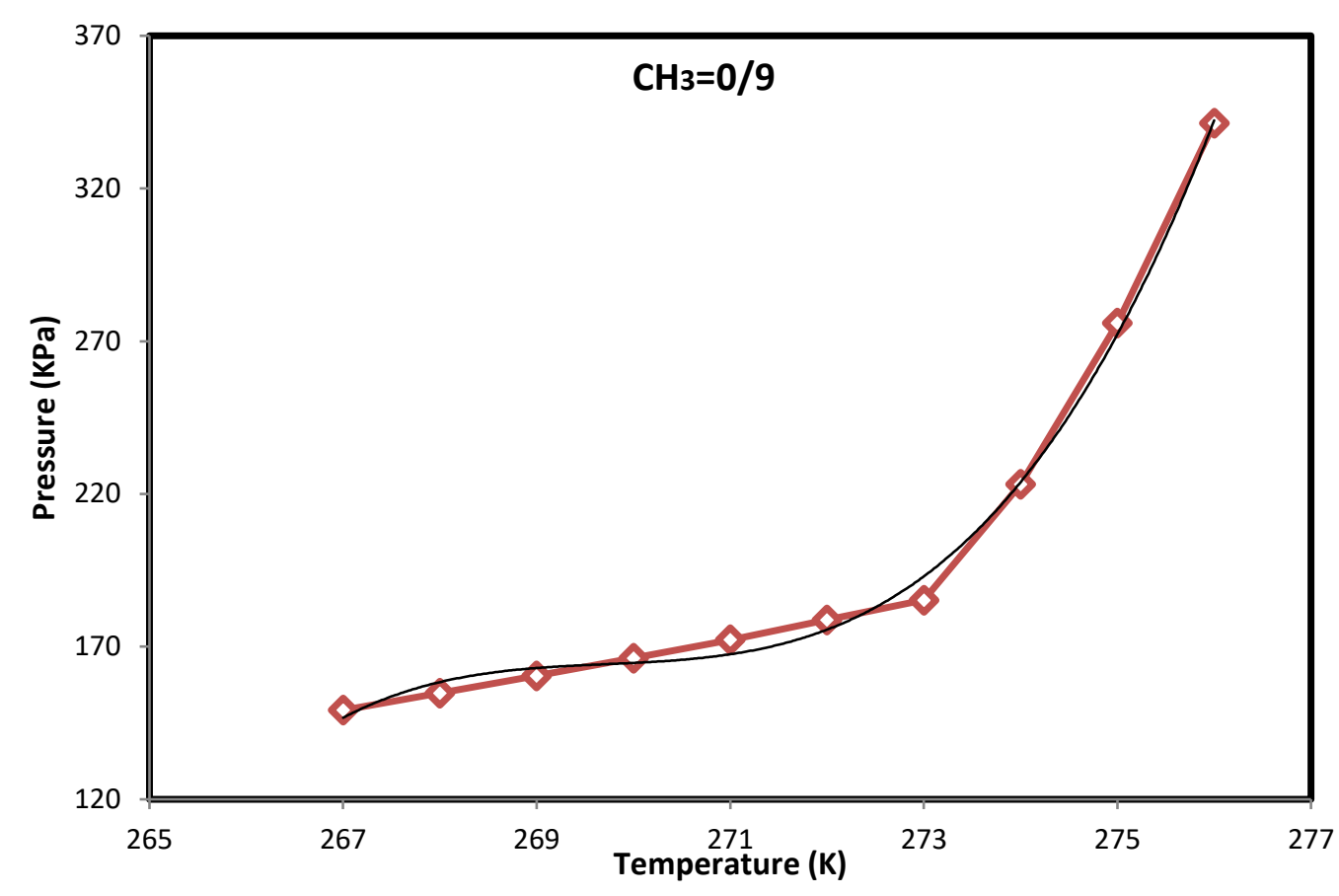

Figure 3- Equilibrium pressure versus temperature @ \% $\mathrm{CH}_{3}=0.9$

Requirements for hydrate formation include low temperature, high pressure and the presence of natural gas or light hydrocarbons in the presence of water. Therefore, one of these three essential factors must be eliminated or controlled to prevent the formation of hydrates.

\section{Conclusion:}

Propane hydrate can be used in the storage and transportation of natural gas by the process of gas separation, carbon dioxide absorption from the air, and cold storage. In the present study, the mixed hydrates of propane and normal butane were investigated at a temperature of $267-276 \mathrm{~K}$ and in three molar fractions of $0.7,0.8$ and 0.9 and the equilibrium pressure was obtained. The results obtained by modeling were compared with the existing experimental results and the mathematical equation was presented to predict the hydrate formation conditions.

\section{Reference:}

[1] Y.F. Makogon, Hydrates of Hydrocarbons, Pennwell Publishing Co. Oklahoma, 1997.

[2]. J.carroll, Natural Gas Hydrate A Guide for Engineers, led. Elsevier Science and Technology Books, New York, 2002

[3] Sloan E. D. "Clathrate Hydrates of Natural Gases", Second ed, Mrcel, New York,1998.

[4] J.C. Froberg, O.J. Rojas, P.M. Claesson. "Surface forces and measuring techniques." Int. J. Miner. Process. 56_1999. 1-30.

[5] Guro Aspenes. "The influence of pipeline wettability and crude oil composition on deposition of gas hydrates during petroleum production". Thesis for the degree of Philosophiae Doctor (PhD) at the University of Bergen, 2003.

[6] Xuemei Lang, Shuanshi Fan, Yanhong Wang, Intensification of methane and hydrogen storage in clathrate hydrate and future prospect, Journal of Natural Gas Chemistry, 19(2010)203-209. 
[7] Xiaoming Peng, YufengHu, Yansheng Liu, Chuanwei Jin, Huaijing Lin. Separation of ionic liquids from dilute aqueous solutions using themethod based on CO2 hydrates. Journal of Natural Gas Chemistry 19(2010)81-85

[8] Kouji Maeda, Yoko Katsura, Yusuke Asakuma, Keisuke Fukui. Concentration of sodium chloride in aqueous solution by chlorodifluoromethane gas hydrate.Chemical Engineering and Processing 47 (2008) 2281-2286

[9]Chatty, I, Delahaye , A , Fournaison, L, Petitet,J.p, "Benefits and drawbacks of clathrate hydrates $\therefore$ a review of their areas of interest " Energy conversion and Management,2004

[10] Heiko Conrad. "Tetrahydrofuran clathrate hydrate formation studied by X-ray Raman scattering”. 2009.

[11] E. Dendy Sloan. "Molecular Hydrogen Storage in Novel Binary Clathrate Hydrates". Colorado School of Mines. April 24, 2009.

[12] S. Porgar, S. Saleh Fekr, M. Ghiassi, B. Hashemi Hosseini, Methanol and sodium chloride inhibitors impact on carbon dioxide hydrate formation, South African Journal of Chemical Engineering, March 2018

[13] Kamath, V.A., Holder, G.D., Chem. Eng. Sci., 16, 399 (1984).

[14] Paranjpe, S.G., Patil, S.L., Kamath, V.A., Godbole, S.P., in Proc. 62nd SPE Annual Conference 379, SPE 16871, Dallas, TX, September 27-30 (1987).

[15]Paranjpe, S.G., Patil, S.L., Kamath, V.A., Godbole, S.P., "Hydrate Formation in Crude Oils and Phase Behavior of Hydrates in Mixtures of Methane, Propane, Isobutane, and n-Butane," paper presented at the Third Chemical Congress of North America, Toronto, June 5-10 (1988).

[16] Kashchiev,D. Firoozabadi, A. , "Induction time in crystallization of gas hydrates " Journal of Crystal Growth ,Vol. $250,2003$. 